\title{
Components of fitness and the PGI polymorphism in the freshwater isopod Asellus aquaticus (L). 1. Fecundity selection
}

\author{
A. F. Shihab* and \\ D. J. Heath
}

Department of Biology, University of Essex, Colchester, England.

Differences in reproductive output were studied between genotypes in a population of the isopod Asellus aquaticus polymorphic at the PGI locus. Reproductive output was measured both in terms of the numbers of eggs and the number of offspring per female. Significant differences were found between the three most common genotypes (3/3, $2 / 3,3 / 4$ ) for both measures. $3 / 3$ had the highest reproductive output. Relative to this the output of $2 / 3$ was 65 per cent and of $3 / 4$ only 40 per cent. This pattern was repeated in three separate years.

\section{INTRODUCTION}

Isopods are useful organisms for studying the dynamics of genetic variation in natural populations. This is because they allow the investigator to follow the sampling schedule devised by Christiansen and Frydenberg (1973) designed to detect fitness differences between allozyme genotypes in natural populations during the reproductive phase of the life cycle. Because isopods are viviparous it enables the reproductive output of females of known genotype to be compared; where the species has an annual life cycle and breeds only once this is equivalent to an estimate of lifetime reproductive output. Using samples of fertilised females, sterile females, males and random offspring allows a detailed analysis of sexual and gametic selection (Christiansen and Frydenberg, 1973). In species that display precopula (Ridley, 1983) an independent analysis of sexual selection can be achieved, a refinement not available in an organism such as Zoarces viviparus (Christiansen, Frydenberg and Simonsen, 1973).

The freshwater isopod Asellus aquaticus has an annual life cycle in most of Britain (Shibhab, 1985) and has a precopula making it an almost ideal organism for these studies. Verspoor (1983) demonstrated that this species is polymorphic for the enzyme phosphoglucose isomerase (PGI, EC5.3 1.9). There are four relatively common

\footnotetext{
* Department of Biology, College of Science, University of Basrah, Basrah, Iraq.
}

alleles at this locus, the frequencies of which seem to be correlated (both spatially and temporally) with water temperature and oxygen concentration. The work presented here formed part of a detailed 3 year study into the dynamics of this variation in one population and describes differences in reproductive output between genotypes. Further papers will consider aspects of sexual and zygotic selection.

\section{METHODS}

Full details of the methods are given by Shihab (1985) so only an outline is given here. The population selected for sampling occurred in a freshwater lake on the University of Essex campus (map ref. TM168 031241). Samples of isopods were taken with a fine mesh net every two weeks from the same area of the lake, from 15 March 1982 to 30 August 1984. Four alleles at the PGI locus were detected by horizontal starch gel electrophoresis. These alleles were numbered 1, 2, 3, 4 in order of increasing mobility. Of the 16 possible genotypes three predominated, $3 / 3$ (frequency between $0 \cdot 60$ $0.75), 2 / 3(0 \cdot 10-0 \cdot 30)$, and $3 / 4(0.05-0 \cdot 20)$. Another three were less common, $1 / 3(0.07-0.01)$, $2 / 4(0 \cdot 01-0.04)$, and $2 / 2(0.02)$ and the remainder were very rarely encountered. There were two distinct breeding seasons each year. In the first ovigerous females, mating animals and females carrying young were found from January-May. 
The offspring were released in June, the parents then dying. These offspring comprise the early summer cohort (e.s.c.), a few of which grow sufficiently to breed from late July-October, producing the late summer cohort (1.s.c.) (Shihab, 1985).

To estimate the mean number of eggs carried, ovigerous females were measured (body length) the eggs dissected out and counted and the female electrophoresed. To estimate fecundity (mean number of offspring released), individual fertilised females captured in the field were isolated in petri dishes of lake water with decaying leaves for food. The number of young released was counted, the female was then measured and genotyped. To investigate possible paternal effects on female fertility mating pairs (in precopula) were collected from the field and placed in petri dishes as before. After offspring release both parents were electrophoresed and numbers of offspring counted. Mean numbers of eggs and young for females of different genotypes were compared using single classification analysis of variance (Sokal and Rohlf, 1981). When the tests yielded significant differences, a posteriori, unplanned comparisons among means were made by the GT2 method (Sokal and Rohlf, 1981). Similar tests were employed on mean female body length since both fertility and fecundity in Asellus are positively correlated with body size (Ridley and Thompson, 1979).

\section{RESULTS}

These are presented in summary form in table $1(\mathrm{a})$ egg number, 1(b) offspring number and 1(c) male effects; full data are given by Shihab (1985).

\section{(a) Mean egg number}

Data were collected from the females which produced the early summer cohort in all three years, but the later, smaller breeding season was only analysed in 1983. In all three years and for both breeding seasons (in 1983) the results were consistent. The mean numbers of eggs produced by different genotypes were significantly different but this could not be attributed to differences in female body size between genotypes. The general pattern was also the same with the $3 / 3$ homozygote consistently producing the highest numbers of eggs (about 120, on average) compared to the other common genotypes $(2 / 3,3 / 4,1 / 3,2 / 4)$ which produced around 70-90 eggs. The females which gave rise to the late summer cohort were of smaller average size and had lower egg production than those that bred earlier, but $3 / 3$ still produced more eggs. When individual pairs of mean values are compared $3 / 3$ consistently produced more eggs than $2 / 3$ and $3 / 4$ but there were no detectable differences between the latter two genotypes. In 1982 and $19833 / 3$ produced significantly more eggs than $1 / 3$ and also $2 / 4$ (in 1983) in the early summer breeding but not in the late summer breeding. However sample sizes of these rarer genotypes were small.

\section{(b) Mean offspring number (fecundity)}

Table 1(b) shows a similar pattern to the previous one with significant differences in the mean numbers of offspring of different genotypes every year but no differences in mean female size. Once again the $3 / 3$ genotype produced the most offspring (about 80 , in the early summer) compared to the other genotypes which produced between 30 and 60 . Comparison of pairs of means shows that the differences between $3 / 3$ and $2 / 3,3 / 4$ and $1 / 3$ were significant although there were no detectable differences between the latter three genotypes. There is a suggestion that both $2 / 4$ and $2 / 3$ had higher fertilities than $3 / 4$ and $1 / 3$ but this was not significant. Late summer breeding females were once again smaller and produced fewer offspring than early summer breeders but again $3 / 3 \mathrm{did}$ significantly better than $2 / 3$ and $3 / 4$. Mean offspring numbers for a given genotype were always lower than mean egg numbers. The figures imply that up to 50 per cent of the eggs carried by a female fail to develop into offspring.

\section{(c) Male effects}

Only one female genotype (3/3) was sufficiently common to provide enough data for this analysis. Each column in table 1(c) gives the average number of offspring (o) produced by $3 / 3$ females found in precopula with males of each genotype. Only the data for 1983 showed significant heterogeneity, with females fertilised by $3 / 3$ males producing the most offspring, significantly more than those fertilised by $2 / 3$ males. The direction of this difference was the same in 1982, but not significant, possibly due to the smaller sample size.

\section{DISCUSSION}

There are marked, consistent, differences between genotypes in fecundity. The fitness of $2 / 3$ and $3 / 4$ 
Table 1 Egg number and offspring number (fecundity) of PGI genotypes. e = average no of eggs, o= average no of offspring, $\mathrm{l}=$ average body length of female, $\mathrm{n}=$ sample size, $\mathrm{bpm}=$ broad pouch mortality $(\%)$, l.s.c. $=$ late summer cohort, e.s.c. $=$ early summer cohort, $\mathrm{F}=$ variance ratio, d.f. $=$ degrees of freedom, ${ }^{* *} \mathrm{p}<0.01,{ }^{* * *} \mathrm{p}<0.001$. Mean values connected by horizontal bars are significantly different. For tables $1(\mathrm{a})$ and 1(b) the vertical columns labelled genotype refer to females. For table 1(c) the columns refer to males (see text for explanation)

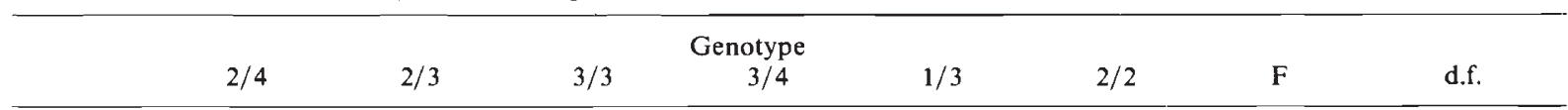

\section{(a) Egg Number}

\begin{tabular}{|c|c|c|c|c|c|c|c|c|c|}
\hline 1982 & $\mathrm{e}$ & $104 \cdot 42$ & $92 \cdot 61$ & $120 \cdot 50$ & $79 \cdot 20$ & $76: 00$ & & $8 \cdot 47^{* * *}$ & 4,124 \\
\hline e.s.c & $\begin{array}{l}\text { l } \\
n\end{array}$ & $\begin{array}{c}9 \cdot 21 \\
7\end{array}$ & $\begin{array}{l}8 \cdot 88 \\
18\end{array}$ & $\begin{array}{l}9 \cdot 17 \\
78\end{array}$ & $\begin{array}{l}8 \cdot 86 \\
15\end{array}$ & $\begin{array}{l}8 \cdot 77 \\
11\end{array}$ & - & 0.97 & \\
\hline 1983 & $\mathrm{e}$ & $75 \cdot 18$ & $79 \cdot 45$ & 118.98 & $78 \cdot 56$ & $76 \cdot 66$ & & $15.07^{* * *}$ & 4,113 \\
\hline e.s.c & $\begin{array}{l}1 \\
n\end{array}$ & $\begin{array}{l}8 \cdot 27 \\
11\end{array}$ & $\begin{array}{l}8 \cdot 72 \\
20\end{array}$ & $\begin{array}{l}9 \cdot 08 \\
62\end{array}$ & $\begin{array}{l}9 \cdot 12 \\
16\end{array}$ & $\begin{array}{l}9 \cdot 05 \\
9\end{array}$ & & $2 \cdot 34$ & \\
\hline $\begin{array}{l}1983 \\
\text { l.s.c }\end{array}$ & $\begin{array}{l}\mathrm{e} \\
\mathrm{l} \\
\mathrm{n}\end{array}$ & - & $\begin{array}{c}33 \cdot 90 \\
5 \cdot 15 \\
10\end{array}$ & $\begin{array}{c}53 \cdot 50 \\
5 \cdot 27 \\
24\end{array}$ & $\begin{array}{c}32 \cdot 83 \\
5 \cdot 16 \\
6\end{array}$ & $\begin{array}{r}32 \cdot 66 \\
5 \cdot 50 \\
3\end{array}$ & $\begin{array}{r}35 \cdot 50 \\
5 \cdot 37 \\
4\end{array}$ & $\begin{array}{l}6 \cdot 43^{* * * *} \\
0.31\end{array}$ & 4,42 \\
\hline $\begin{array}{l}1984 \\
\text { e.s.c }\end{array}$ & $\begin{array}{l}\mathrm{e} \\
1 \\
\mathrm{n}\end{array}$ & $\begin{array}{c}82 \cdot 77 \\
8.66 \\
9\end{array}$ & $\begin{array}{c}85 \cdot 78 \\
8 \cdot 86 \\
19\end{array}$ & $\begin{array}{c}124 \cdot 20 \\
9.03 \\
53\end{array}$ & $\begin{array}{r}68 \cdot 58 \\
8 \cdot 88 \\
17\end{array}$ & $\begin{array}{r}69 \cdot 87 \\
8 \cdot 75 \\
8\end{array}$ & - & $\begin{array}{c}18.22^{* * *} \\
0.47\end{array}$ & 4,101 \\
\hline
\end{tabular}

(b) Offspring Number

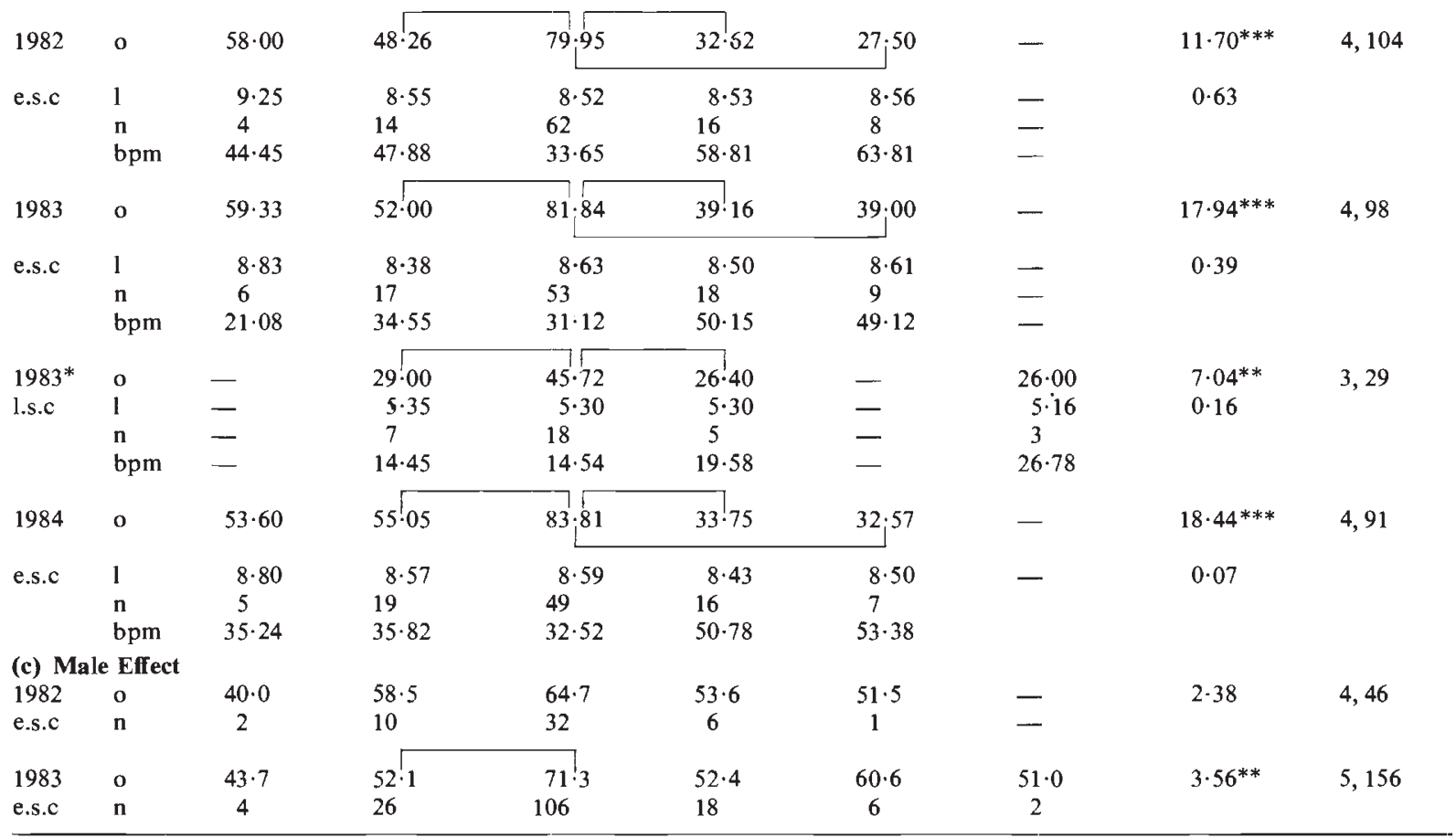

relative to $3 / 3$ are about 0.65 and 0.4 respectively. Such large fitness differences arising from fecundity selection between allozyme genotypes have never been reported although information is scarce. Marinkovic and Ayala (1975) showed that one of the homozygotes at the esterase- 5 locus in Drosophila pseudoobscura had a fecundity of about 90 per cent compared to the two other genotypes. 
A similar difference was observed between octanol dehydrogenase genotypes but not between $\mathrm{MDH}$ genotypes. Edwards and Heath (1983) reported that genotypes at the phosphoglucose isomerase locus in the estuarine isopod Sphaerona rugicauda differed in fecundity; fast homozygotes and heterozygotes had a fitness of about 0.8 compared to slow homozygotes. Sassaman (1978), on the other hand detected no fecundity differences between LDH genotypes in the woodlouse Porcellio scaber, and the same was true of the investigation by Christiansen et al. (1973) of esterase genotypes in the fish Zoarces viviparus.

Part of the fecundity difference observed here is clearly due to differences in the numbers of unfertilised eggs carried by the different genotypes. The differences in both cases are in the same direction and of the same order of magnitude. In all cases females carry more eggs than they produce offspring implying that not all eggs develop successfully. This brood pouch mortality has been described previously in Asellus (Steel, 1961) and is a common feature of isopod reproductive biology (Heath and Khazaeli, 1985) although it is not clear whether it arises pre- or post-fertilisation or whether it results from expulsion or resorption of reproductive products. Clearly if there are differences in the rate of brood pouch mortality between genotypes they will modify fecundity differences due to differential egg production. There is some evidence of this from table 1. 3/3 homozygotes always have the lowest brood pouch mortality, followed by $2 / 4$ and $2 / 3$, then $3 / 4$ and $1 / 3$, (Brood pouch mortality is simply calculated as the average number of offspring produced by a genotype expressed as a percentage of the average number of eggs carried by that genotype and subtracted from 100.)

Additional evidence for this comes from the limited data on male effects which showed that $3 / 3$ females mated with $3 / 3$ males produced the most offspring. A similar effect was described by Verspoor (1983) who suggested that the reproductive output of pairs where the male was $2 / 2$ could be 30 per cent higher than those where the male was $2 / 3$ or $3 / 3$. Since effects of maternal genotype on egg numbers are controlled for, the subsequent differences in fecundity must have other causes. Such effects could arise because the paternal genotype (diploid) affects fertilisation success by better "outfitting" of sperm prior to ejaculation (Gilbert and Richmond 1982) or because the haploid sperm genotype affects fertilisation efficiency. Finally the diploid zygote genotype may affect prenatal viability. It is not possible to dis- criminate between these hypotheses on the available data but they could all affect the proportion of eggs which successfully develop in different genotypes and thus contribute to brood pouch mortality.

In the absence of some disadvantage this strong directional selection in favour of $3 / 3$ should lead rapidly to a population monomorphic for the 3 allele yet all the indications are that genotype frequencies have been stable over the past 3 years (Shihab, 1985). Fitness differences between some of the other genotypes in survival and mating ability have been clearly demonstrated (Shihab, 1985 ) but no disadvantage of the $3 / 3$ genotype has been found. Its frequency in the population increases to a maximum of 75 per cent during the production of the early summer cohort (as the fecundity differences would predict). The frequency then falls to 60 per cent in December and January suggesting that it has a lower winter survival but there is no experimental evidence for this.

An additional interesting observation from table 1 concerns the $2 / 2$ genotype (frequency 0.02 $0.03)$. This does not appear amongst the females which contribute towards the early summer cohort in 1983 despite the relatively large sample sizes but is proportionately over-represented in females producing the late summer cohort. Its rarity in early breeding animals is supported by an independent analysis of sexual selection (Shihab, 1985). $2 / 2$ is less common than expected among animals mating to produce the early summer cohort. The data presented here would suggest that its disadvantage in not reproducing early in the year may be counterbalanced by an above average ability of $2 / 2$ juveniles to grow and reproduce later in the year in which they were born.

Obviously the data presented here do not identify the target of selection as variation at the PGI locus rather than variation at a linked locus. This can only be resolved by the direct approach as employed by Hilbish and Koehn (1985), Watt (1983) and Burton and Feldman (1983) where in vitro differences in allozyme biochemistry are linked to in vivo differences in biochemistry, physiology and fitness. There is in the literature a growing body of evidence showing both that PGI allozymes vary in their in vitro properties e.g. Hoffman (1981), Hall (1985) and that these differences can translate into in vivo differences in fitness e.g., Watt (1983). This is not surprising given the role of PGI in glycolysis and makes it not unreasonable to posit a direct causal connection in Asellus. 


\section{REFERENCES}

BURTON, R. S. AND FELDMAN, M. W. 1983. Physiological effects of an allozyme polymorphism: glutamate-pyruvate transaminase and response to hyperosmotic stress in the copepod Tigriopus californicus. Biochem. Genet., 21, 239 251.

CHRISTIANSEN, F. B. AND FRYDENBERG, O. 1973. Selection component analysis of natural polymorphisms using population samples including mother-offspring combinations. Theor. Pop. Biol., 4, 425-445.

CHRISTIANSEN, F. B., FRYDENBERG, O. AND SIMONSEN, V 1973. Genetics of Zoarces populations. IV. Selection component analysis of an esterase polymorphism using population samples including mother-offspring combinations. Hereditas, 73, 291-304.

EDWARDS, J. P. AND HEATH, D. J. 1983. Dynamics of an enzyme polymorphism in the isopod. Sphaeroma rugicauda (Leach). II. Sexual, gametic and fecundity selection. Heredity $51,477-486$.

GILBERT, D. G. AND RICHMOND, R. L. 1982. Esterase 6 in Drosophila melanogaster: Reproductive function of active and null males at low temperature. Proc. Natl. Acad. Sci. USA, 79, 2962-2966.

HALL, J. G., 1985. Temperature related kinetic differentiation of glucose phosphate isomerase alleloenzymes isolated from the blue mussel, Mytilus edulis. Biochem. Genet. 23, 705-729.

HEATH, D. J. AND KhazAELI, A. A. 1985. Population dynamics of the estuarine isopod, Sphaeroma rugicauda. Estuarine Coastal and Shelf Sci., 20, 105-116.

HILBISH, T. J. AND KOEHN, R. K. 1985. The physiological basis of natural selection at the Lap locus. Evolution, 39, 1309 1317.
HOFFMAN, R. J. 1981. Evolutionary genetics of Metridium senile I. Kinetic differences in phosphoglucose isomerase allozymes. Biochem. Genet., 19, 145-144.

MARINKOVIC, D. AND AYALA, F. J. 1975. Fitness of allozyme variants in Drosphila pseudoobscura. II. Selection at the Est-5, Odh and Mdh-2 loci. Genet. Res., 24, 137-149.

RIDLEY, M. 1983. The explanation of organic diversity. Clarendon Press, Oxford.

RIDLEY, M. AND THOMPSON, D. J. 1979. Size and mating in Asellus aquaticus (Crustacea: Isopoda). Z. Tierpsychol., 51, 380-397.

SASSAMAN, C. 1978. Dynamics of a lactate dehydrogenase polymorphism in the woodlouse Porcellio scaber Latr: Evidence for partial assortative mating and heterosis in natural populations. Genetics, 88, 591-609.

SHIHAB, A. 1985. Dynamics of an enzyme polymorphism in the isopod Asellus aquaticus. Ph.D. Thesis, University of Essex.

SOKAL, R. R. AND ROHLF, F. J. 1981. Biometry. W. H. Freeman and Company, San Fransisco.

STEEL, E. A. 1961. Some observations on the life history of Asellus aquaticus (L) and Asellus meridianus (Racovitza). Proc. Zool. Soc. Lond., 137, 71-87.

VERSPOOR, E. 1983. Allozyme frequencies in Western European populations of Asellus aquaticus (L) Isopoda and their association with water pollution. Biol. J. Linn. Soc., 19, 275-293.

WATT, W. B. 1983. Adaptation at specific loci II. Demographic and biochemical elements in the maintenance of the Colias PGI polymorphism. Genetics, 103, 691-724. 